\title{
Frédéric Saenen, Drieu la Rochelle face à son œuvre
}

\section{Michela Gardini}

\section{(2) OpenEdition}

\section{Journals}

\section{Edizione digitale}

URL: http://journals.openedition.org/studifrancesi/4459

DOI: 10.4000/studifrancesi.4459

ISSN: 2427-5856

\section{Editore}

Rosenberg \& Sellier

\section{Edizione cartacea}

Data di pubblicazione: 1 settembre 2016

Paginazione: 361

ISSN: 0039-2944

\section{Notizia bibliografica digitale}

Michela Gardini, «Frédéric Saenen, Drieu la Rochelle face à son œuvre », Studi Francesi [Online], 179 (LX

II) | 2016, online dal 01 septembre 2016, consultato il 18 septembre 2020. URL : http://

journals.openedition.org/studifrancesi/4459; DOI : https://doi.org/10.4000/studifrancesi.4459

Questo documento è stato generato automaticamente il 18 settembre 2020 .

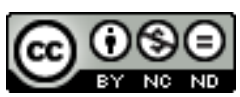

Studi Francesi è distribuita con Licenza Creative Commons Attribuzione - Non commerciale - Non opere derivate 4.0 Internazionale. 


\title{
Frédéric Saenen, Drieu la Rochelle face à son cuvre
}

\author{
Michela Gardini
}

\section{NOTIZIA}

FRÉDÉRIC SAENEN, Drieu la Rochelle face à son cuvre, Gollion, Infolio, 2015, 198 pp.

1 Entrato nella Pléiade nel 2012, Drieu la Rochelle è diventato oggetto di studio da alcuni anni, come dimostra anche il recente saggio di Frédéric Saenen, il cui merito principale risiede nell'imparziale equilibrio con cui viene analizzata l'opera dello scrittore senza per questo che venga omessa né ridimensionata l'imbarazzante adesione di Drieu al progetto politico che troverà nel nazismo il proprio approdo. Profondamente abitato dall'ossessione della decadenza della Francia, Drieu aveva riconosciuto nella Germania di Hitler l'unico stato europeo capace di realizzare quella vasta autarchia in grado di restituire all'Europa un ruolo di prim'ordine nel panorama mondiale, come lo scrittore afferma nei suoi scritti non solo saggistici ma soprattutto intimistici, quali il Journal, redatto dal 1939 al 1945 ma diffuso solamente a partire dal 1991 e Récit secret, pubblicato postumo dal fratello nel 1961. Opere queste ultime, inoltre, attraversate dalla tentazione suicida dello scrittore, che metterà fine alla propria vita il 15 marzo 1945 all'età di cinquantadue anni.

D'altra parte anche i romanzi presentano non pochi elementi autobiografici che Saenen ripercorre dettagliatamente, da Feu follet (1931) a Beloukia (1936), sino al più famoso Gilles (1939). Saenen compone un saggio al contempo biografico e critico, nel tentativo riuscito di rintracciare e analizzare gli intrecci storici, ideologici, culturali nonché letterari alla base dell'intera vicenda di Drieu la Rochelle.

Di agevole lettura, il saggio presenta alcuni approfondimenti, messi in rilievo da una veste tipografica diversa, volti a documentare e chiarire alcuni aspetti peculiari, come, per esempio, il rapporto di Drieu con il Surrealismo, al quale aderì inizialmente per poi distaccarsene, oppure il confronto con altri scrittori suoi contemporanei, quali Barrès e 
Céline e, cruciale, l'adesione al Parti Populaire Français fondato da Jacques Doriot nel 1936, noto per la sua posizione collaborazionista. 